\title{
Ações didáticas para a inserção da leitura na alfabetização: estudo de caso de uma professora alfabetizadora
}

\author{
Ana Gabriela de Souza Seal \\ Universidade Federal Rural do Semi-Árido - UFERSA
}

\begin{abstract}
Resumo
A pesquisa revela ações didáticas realizadas por uma docente dos anos iniciais do ensino fundamental no tratamento destinado à área da leitura em uma turma de segundo ano do primeiro ciclo. Foi possível observar que a docente propunha uma rotina diversificada, como também atividades com o mesmo desenvolvimento/apresentação, porém com níveis diferentes de dificuldades. É relevante salientar que as ações e escolhas didáticas da docente alfabetizadora em prol do ensino da leitura estiveram intimamente relacionadas com a necessidade de levar os alunos à aprendizagem da linguagem enquanto sistema e enquanto instrumento social.

Palavras-chave: Leitura; Alfabetização; Ações Didáticas.
\end{abstract}

\begin{abstract}
This research discusses didactic actions carried out by a teacher in the initial years of elementary school, in the treatment of reading in a second year class in the first cycle. It was observed that the teacher proposed a diversified routine as well as activities with the same development / presentation but with different levels of difficulties. It is important to point out that the actions and didactic choices of the literacy teacher for the teaching of reading were closely related to the need to lead students to learn language as a system and as a social instrument.
\end{abstract}

Key words: Reading; Literacy; Didactic Actions.

\section{INTRODUÇÂO}

Em meio à prevalência do discurso em prol da alfabetização conjugada ao letramento - dois termos que merecem atenção constante - nos deparamos com um processo intenso de apropriação pelas/pelos docentes dos discursos e práticas recentes no que tange ao ensino da leitura na alfabetização.

A ação de alfabetizar baseada na perspectiva do letramento tem fomentado fortes discussões no campo educacional brasileiro e impulsionado programas de formação docente de professores alfabetizadores, inclusive via programas governamentais - vejase, como exemplo, o Pacto Nacional pela Alfabetização na Idade Certa - PNAIC (BRASIL, 2012). A revisão de orientações curriculares, a revisitação aos materiais didáticos e um controle de qualidade dos livros didáticos de alfabetização distribuídos às 
escolas públicas têm ampliado a divulgação das formas de fazer a alfabetização com base no letramento. A inserção das crianças de seis anos no ensino fundamental, mais recentemente, contribuiu para a valorização e fortalecimento dessa perspectiva à medida que privilegiou um discurso acerca da necessidade de uma alfabetização contextualizada na vivência dos discentes. Orientações publicadas e discutidas em cursos de formação continuada via Ministério da Educação têm disseminado análises, planejamentos e ações que rompem com os antigos métodos de alfabetização e propõem a reflexão-ação baseada em diferentes propostas metodológicas em contributo à criação de espaços de aprendizagem que resgatam a função social da linguagem. Nesse ínterim encontram-se os docentes - expostos às políticas, formações, materiais e reflexões fomentadas por esse campo de conhecimento em ascensão - realizando escolhas didáticas que os aproximam ou distanciam do discurso em pauta, ao mesmo tempo em que geram apropriações e novas necessidades para o estabelecimento de sua prática pedagógica.

Acerca das práticas de alfabetização, em particular, nosso olhar se volta para as ações e escolhas didáticas de docentes em prol do ensino da leitura. Sobre essa questão, é importante considerar que diante da perspectiva do alfabetizar-letrando, a aprendizagem da leitura se faz enquanto demanda pertinente e urgente mesmo quando ainda não se sabe ler com autonomia. As estratégias utilizadas por um leitor fluente passam a ser alvo de problematização já no inicio do processo de alfabetização, pelo justo reconhecimento da função social da linguagem. Nossa investigação se pautou na análise de como as preocupações docentes acerca desse aspecto são materializadas no âmbito da sala de aula.

Esta pesquisa é um recorte de um estudo intitulado "Práticas de Leitura nos Anos 1 e 2 do Ensino Fundamental: ações docentes para alfabetizar letrando" (SEAL, 2012). No estudo, acompanhou-se, no ano de 2012, as práticas de cinco professoras alfabetizadoras, que resultou em 76 protocolos de aulas, totalizando aproximadamente 300 horas observadas. A seguir apresentaremos as concepções acerca da ação de alfabetizar letrando que guiam as análises dessa pesquisa, bem como o que estamos considerando por ações e escolhas didáticas, para, enfim, expor nossa orientação acerca do ensino de leitura no processo de alfabetização. Por fim, apresentaremos o resultado das análises de 12 aulas de uma docente alfabetizadora do segundo ano do primeiro ciclo com enfoque em suas ações e escolhas didáticas para a promoção da leitura em sua turma de alfabetização. 


\section{ALFABETIZAÇÃO E LETRAMENTO: CONCEITOS PRIMORDIAIS}

Não menosprezando a relevância dos processos educacionais externos ao ambiente escolar, torna-se fundamental compreender os aspectos que têm envolvido a alfabetização nas salas de aulas. É nessa instância de investigação que nos situamos e é, por meio dela, que precisamos explicitar o que estamos concebendo por alfabetização. Passamos a assumir, portanto, o termo alfabetização em sua acepção mais singular, que se refere à aprendizagem propriamente dita da escrita alfabética. Sem entrar, nesse momento, no mérito das abordagens acerca de seu(s) antônimo(s) ou variações, já muito bem discutidos e aprofundados por Soares (1998; 2003), tomemos por base a situação mesma de ensino-aprendizagem da escrita alfabética promovida na escola.

Sobre essa questão, é relevante destacar que as abordagens acerca dos métodos não podem ser consideradas, hoje, abandonadas. Há permanências que podem ser perceptíveis quando da análise das situações didáticas estabelecidas ou mesmo ao se questionar os próprios professores. Ainda assim, é possível, igualmente, identificar mudanças, seja no processo de agregar os novos conhecimentos à alfabetização para orientar as práticas, ou na tomada de atitudes ante as mediações mais localizadas.

O momento em destaque possui sua relevância por revelar um novo modo de encarar os processos de alfabetização. A concepção sobre a alfabetização se distancia de sua articulação com os métodos - e materialização por meio desses, se se passa a compreender que os métodos eram representados por suas próprias cartilhas (CHARTIER, 2007, p. 70) - considerando o sujeito cognoscente (MORTATTI, 2000, p. 253), o papel do professor e da escola na realização dessa atividade.

Soares (2003) tece apontamentos para a necessidade de se reinventar a alfabetização, sem dissociá-la do letramento. Reconhece-se, dessa forma, o âmbito da aquisição do sistema convencional de escrita e das competências de ler e escrever, em paralelo ao desenvolvimento das habilidades de seu uso. A autora explicita a fundamental tarefa de exploração dessas duas instâncias pelas instituições escolares, uma vez que os considera como:

(...) processos de natureza fundamentalmente diferente, envolvendo conhecimentos, habilidades e competências específicos, que implicam formas de aprendizagem diferenciadas e, consequentemente, procedimentos diferenciados de ensino (SOARES, 2003, p. 15).

Da mesma autora (SOARES, 1998), em sua obra clássica "Letramento: um tema em três gêneros" há a apresentação do que ela considerou um verbete, publicado na 
revista "Presença Pedagógica". A priori, retomado do Aurélio, alfabetizar seria ensinar a ler. Alfabetização, a ação de ensinar a ler, ao que acrescentou a autora, "e também a escrever" (SOARES, 1998, p. 16). Ampliando, ela retoma a discussão para apresentar a alfabetização num âmbito individual e social.

Em outras palavras: do ponto de vista individual, o aprender a ler e escrever alfabetizar-se, deixar de ser analfabeto, tornar-se alfabetizado, adquirir a "tecnologia" do ler e escrever e envolver-se nas práticas sociais de leitura e de escrita - tem consequências sobre o indivíduo, e altera seu estado ou condição em aspectos sociais, psíquicos, culturais, políticos, cognitivos, linguísticos e até mesmo econômicos; do ponto de vista social, a introdução da escrita em um grupo até então ágrafo tem sobre esse grupo efeitos de natureza social, cultural, política, econômica, linguística. O "estado" ou a "condição" que o indivíduo ou o grupo social passam a ter, sob o impacto dessas mudanças, é que é designado por literacy.

Se alfabetizar diz respeito à instância individual do aprender a ler e escrever, para fazer uso nas práticas sociais, o letramento diz respeito ao enfoque social do aprender a ler e escrever. E, se, na alfabetização, se fala de uso da tecnologia de leitura e escrita, no letramento se convoca o "estado" ou "condição" promovido pelo uso dessa tecnologia.

Segundo Soares (1998), a ênfase dada à ausência de ações do letrar nos últimos anos, sobretudo após a revelação da ocorrência de um analfabetismo funcional, gerou nas escolas uma atitude de fazer uso de diversos gêneros discursivos e colocá-los à análise pelos alunos. Tal iniciativa, juntamente com outros fatores de igual ou maior relevância que influíram em mudanças no contexto escolar, foi implementada em meio à crítica aos diversos métodos de alfabetização, o que contribuiu para o abandono do ensino sistemático da escrita alfabética, criando novo quadro problemático, revelado por meio de avaliações externas à escola que indicaram um grande contingente de alunos não alfabetizados após um período de quatro anos ou mais de escolarização (Ibidem, p. 9).

\section{Ações e escolhas didáticas para a conjugação da alfabetização e do letramento}

As ações e escolhas didáticas acerca da alfabetização e do letramento já foram alvo de diversas pesquisas acadêmicas. Alguns de seus resultados revelam práticas docentes orientadas por perspectivas construtivistas de alfabetização que intencionaram conjugar a alfabetização e o letramento, por meio de propostas de elaboração de atividades, de avaliação, de mediação.

Cruz (2008) procurou analisar práticas de alfabetização e letramento, implementadas no primeiro ciclo de uma escola da rede municipal do Recife, 
relacionando-as às aprendizagens dos alunos. A autora observou aulas em três turmas $\left(1^{\circ}\right.$, $2^{o}$. e $3^{o}$. Anos do primeiro ciclo) de uma mesma escola, que tinha tido bons resultados numa avaliação em larga escala da qual aquela rede participou. Além disso, avaliou os conhecimentos dos alunos sobre o Sistema de Escrita Alfabética - SEA, sobre a compreensão leitora e a produção de textos. Os resultados desse estudo foram reveladores. A autora aponta que a turma de primeiro ano estudada concluiu o ano escolar contabilizando cerca de $86 \%$ de crianças tendo atingido a hipótese alfabética de escrita. Identificou-se também uma progressão entre os três anos do primeiro ciclo e, como um terceiro dado, a escola mantinha vigilância sobre os alunos do terceiro ano que apresentassem dificuldades em relação à aprendizagem da escrita, evitando possíveis evasões. A esses resultados, Cruz (2008) considera que as práticas alfabetizadoras estabelecidas pelas docentes se constituem como fator primordial para o sucesso escolar.

Enquanto práticas de alfabetização estabelecidas, a pesquisadora identificou que, na maior parte do tempo de aula dessas professoras, os alunos eram conduzidos à utilização efetiva e contextualizada da leitura e da escrita, das quais o primeiro ano recebeu atenção especial, no que tange aos espaços de desenvolvimento de atividades em prol da aprendizagem da escrita alfabética. Já as atividades de leitura e escrita, observadas nos três anos, ganharam ênfase no terceiro ano. Dentre as atividades identificadas nos oito dias de observação em cada turma, foi possível listar a leitura de chamada, enunciados, planejamento e de diversos gêneros discursivos; produção de textos diversos, com ou sem reflexão gramatical e de pontuação; atividades de análise linguística voltadas ao ensino da escrita alfabética (sobretudo no primeiro ano) ou para o ensino de outras competências e atividades diversificadas, com base no uso de livros didáticos, jogos, dentre outras.

Se pensarmos, especificamente, na conjugação das atividades de leitura e de escrita às de apropriação do sistema alfabético, a pesquisa de Albuquerque, Morais e Ferreira (2008) nos traz evidências importantes. Esses autores demonstraram que existem níveis de interação entre esses tipos de atividades (de ensino do SEA e de ensino de leitura de textos) variados no interior das salas de aula. Em uma pesquisa realizada com um grupo de nove professoras do primeiro ano do ensino fundamental da rede do Recife, no ano de 2004, foram identificados dois tipos de práticas, classificadas como assistemáticas e sistemáticas, de professoras que partiam de uma concepção construtivista de ensino-aprendizagem, de acordo com o que fora coletado em 10 encontros de observação. No primeiro grupo, de práticas assistemáticas, era possível 
perceber o desenvolvimento de atividades de leitura e de escrita de textos, sem o desenvolvimento de atividades de análise acerca da escrita alfabética, ou com pouca ênfase sobre essas. O segundo grupo de docentes, conjugava as práticas de leitura e de escrita às atividades de apropriação do sistema alfabético de escrita, inclusive, variando seus tipos. Nesse segundo grupo foram propostas, inclusive, atividades em prol do desenvolvimento da consciência fonológica. Um estudo sobre o rendimento dos alunos daquelas mesmas turmas (cf. ALBUQUERQUE, MORAIS, FERREIRA, 2006) revelou que, nas salas em que se praticava um ensino sistemático do SEA, conjugado ao ensino de leitura e produção de textos, o percentual de alunos que ao final do ano tinham alcançado uma hipótese alfabética de escrita (79\% a 85\%) era sempre mais alto que nas turmas submetidas ao ensino assistemático.

A pesquisa de Cruz (2008) aponta igualmente para a necessidade de conjugação dessas instâncias e de variação das propostas e tipos de atividades como um fator relevante para o ensino dos diferentes princípios que regem a escrita alfabética ou de outros conhecimentos que orientam seu registro. Chama nossa atenção, para uma implementação de propostas, no plural, construtivistas de ensino da alfabetização, a pertinência de se pensar numa variedade de atividades que deem conta de todas as demandas colocadas pela aprendizagem da linguagem escrita.

Outra questão a salientar, em particular, diz respeito às circunstâncias em que se apresenta a leitura na escola e a sua garantia nas rotinas das salas de alfabetização, sobretudo para os anos 1 e 2 do ensino fundamental. Sigamos, então com essa abordagem.

\section{A Leitura na alfabetização}

Fazendo um breve recorte das memórias escolares e das pesquisas acerca da História da Alfabetização no Brasil, é possível identificar a presença constante e quase exclusiva das cartilhas para ensinar a ler dentro das instituições de ensino. Mortatti (2000) revelou que esses materiais estiveram conjugados à perspectiva de alfabetização adotada, ou seja, materializavam os métodos que se pretendia implementar e as concepções que embasavam esses métodos. Para essas concepções tradicionais de ensino da alfabetização, eram geralmente implementadas práticas de ensino da leitura em que se priorizava o acesso às partes menores para só então seguir na tentativa de juntá-las e chegar às partes maiores. Essa forma de acesso ao texto não propiciava seu entendimento. 
Eram desconsiderados outros mecanismos de leitura que colaboravam na compreensão do texto, bem como dada extremada relevância a alguns fatores que não geravam, necessariamente, a compreensão.

Diante de tal problemática, Colomer e Camps (2002, p. 33 a 36) salientam que a atuação do leitor encontra-se baseada em processos mentais que fazem uso da percepção, memória e representação do mundo antes de tudo. A percepção seria um primeiro momento de identificação dos estímulos mediante sentidos conservados por pouco tempo no cérebro caso não se incorporem aos mecanismos seguintes. A memória inicia o processo de retenção da informação percebida pelos sentidos quando essa aparece como necessária, podendo ser classificada como visual, verbal, significativa, dentre outras. Além disso, ainda é preciso situar a existência das memórias a curto e longo prazo. A memória de curto prazo, também chamada de memória de trabalho, "caracteriza-se por uma capacidade limitada tanto no tempo quanto na quantidade de informação retida" (Ibidem, p. 34). Informação essa que pode ser agregada a contextos mais amplos. A memória de longo prazo "é definida por sua grande duração e capacidade. É graças a essa capacidade que se pode reter tudo o que se sabe sobre o mundo, desde que a informação tenha sido organizada de forma compreensível e seja significativa para o sujeito" (Ibidem, p. 35). No que tange à representação do mundo, as autoras convocam a noção de esquema, definido como "estruturas mentais que o sujeito constrói na interação com o ambiente, e que organizam seu conhecimento e o modo de usá-lo" (Ibidem, p. 35). Os esquemas são aplicáveis em diferentes contextos, mas dependem das variáveis que se colocam em sua utilização para a obtenção de um uso mais proveitoso ou não, ou mesmo para sua reorganização de maneira a integrar mais informações aos esquemas já existentes, "assim, a compreensão e a lembrança da informação não dependem de uma capacidade limitada, mas do domínio de estruturas de conhecimentos pertinentes para processá-la, assim como da habilidade que se tenha desenvolvido para fazê-lo" (Ibidem, p. 36).

Além dessa atuação leitora, Colomer e Camps (2002, p. 36 a 47) ressaltam ainda o uso das estratégias em prol da compreensão leitora. Acerca desse aspecto, Solé (1998) detalha de acordo com os movimentos antes, durante e após a leitura, quais são as estratégias utilizadas por leitores eficientes para enumerar as estratégias passíveis de se tornarem objetos de ensino.

Para além da identificação acerca da função das estratégias, Colomer e Camps (2002, p. 47 a 57) ainda chamam a atenção aos fatores que incidem na compreensão 
leitora, das quais destacam a intenção da leitura e os conhecimentos trazidos pelo leitor, este último representado pelos conhecimentos sobre o escrito e conhecimentos sobre o mundo.

Nessa perspectiva, torna-se fundamental refletir acerca desses preceitos para avaliar até que ponto as práticas instituídas no âmago das salas de alfabetização se voltavam para o ensino da alfabetização conjugado a uma leitura que engendrasse compreensão. Chama-se a atenção para que, após o advento das pesquisas que fundamentaram as correntes construtivistas de ensino, essas práticas tradicionais - porque constituídas num contexto sócio-histórico amplo e por muitos anos, único - de ensino da leitura e alfabetização continuaram a conviver com propostas de ensino mais recentes, gerando práticas - aos olhos externos ao ambiente escolar - híbridas, mas que intencionavam (intencionam) o pleito da compreensão.

Passemos, então a investigar algumas das práticas instituídas em sala de alfabetização por uma docente imbuída da necessidade de levar seus alunos a aprender a ler com autonomia.

\section{AS ESCOLHAS E AÇÕES DIDÁTICAS NUMA TURMA DE SEGUNDO ANO DO PRIMEIRO CICLO}

Selecionamos doze aulas de uma docente de um segundo ano do primeiro ciclo da rede municipal do Recife para apresentar os resultados de suas aulas. Nossa perspectiva metodológica pautou-se na análise de conteúdo de Bardin (1977) e buscou compor um corpus documental baseado em dados verbais coletados via entrevistas semiestruturadas e observações de aulas áudio-gravadas (LANKSHEAR e KNOBEL, 2004). As observações de aulas foram realizadas ao longo de um ano letivo, ano de 2012, e eram realizadas em bloco de quatro aulas por vez. Nesse momento apresentaremos o resultado de três blocos de quatro aulas.

A escolha da escola e da docente esteve relacionada ao alto índice de desenvolvimento da educação básica (IDEB) apresentado pela escola em questão no ano de 2010. Dentre as escolas municipais, esta, em particular, envolvia seus docentes em diversas ações de formação continuada e organizava-se de forma a contemplar no planejamento coletivo projetos de ensino. Igualmente angariou premiações em concursos públicos nos quais seus discentes eram participantes. Buscávamos, ao optar pela escola que revelasse alto IDEB, os docentes que lá se encontravam para identificar o diferencial de suas práticas frente às exigências das avaliações nacionais. 
A docente participante da pesquisa se disponibilizou de pronto quando da apresentação de nossa proposta. Demonstrava interesse na socialização de suas práticas, o que gerou uma abertura maior para a coleta dos dados realizada em sua sala de aula. Esta docente, em entrevista realizada, revelou que possuía cerca de cinco anos de docência no ensino fundamental, e possuía cerca de dois anos e meio nos anos iniciais na rede municipal. Era também professora do ensino superior há cerca de cinco anos, cursava o Doutorado em Educação e tinha 29 anos.

Em entrevista, a professora revelou que sua prioridade era a leitura e a aprendizagem da escrita alfabética. Dentre os materiais utilizados com maior frequência, a professora indicou que usava muitas fichas de atividades, jogos de alfabetização, o próprio livro didático, músicas e textos em geral, dos quais destaca poemas (para trabalhar apropriação e utilizar a rima nesse sentido). Acerca da organização espacial da sala de aula, a docente salientou que o espaço físico de sua sala era um fator de vantagem, considerando que esta era ampla, com ar condicionado e contava com cadeiras e mesas que poderiam ser organizadas de diversas formas. Ela dava preferência à utilização de grupos de quatro alunos, embora também fizesse uso de outras formas de organização destes. Em específico, sobre as atividades de leitura, gostava muito de promover a escuta e leitura de músicas, de modo a levar os discentes a realizarem pseudoleituras, como mais um contributo à sua prática alfabetizadora.

Essas informações evidenciam a perspectiva diferenciada de ensino da alfabetização por que se pautava esta docente, revelando um necessário distanciamento de práticas alfabetizadoras consideradas "adultocêntricas" (FERREIRO, 2001). Além de dar preferência aos gêneros discursivos de interesse dos discentes, a professora indicou a preocupação com o uso contextualizado dos gêneros de textos de modo a tentar congregar essa questão às situações mesmas de ensino da escrita alfabética, seja via exploração de seus princípios, seja por meio de análise das relações linguísticas - gráficas e/ou fonológicas - de semelhanças e diferenças.

Para além das explicitações da docente em entrevistas, suas ações in loco indicaram uma diversidade de possibilidades e de escolhas na criação de espaços de aprendizagem da leitura, da escrita alfabética e das produções textuais. Das doze aulas observadas, foi possível elencar as seguintes ações: organização do cantinho de leitura (todos os dias a professora solicitava ajuda aos alunos para organizarem estantes - cestas plásticas, livros e almofadas), registro do roteiro no quadro, realização de rodas de conversas, realização da Hora do Conto (diariamente), respostas às fichas de atividades 
(de diversas áreas do conhecimento), escuta de músicas, leitura de músicas, utilização de jogos (de alfabetização e outros), produção de cartazes, produção de textos (coletivo, individual - ex. trava-língua, final de contos, crachás), socialização de leituras, leituras livres, visita à livraria, realização de projetos didáticos (ex. reciclagem, Luiz Gonzaga), revisões de textos, utilização de livros didáticos (de diferentes áreas), apresentação de vídeos (ex. de contação de história, vídeos informativos), palestras, dentre outras ações menos relevantes para este momento. As figuras 1 a 6 ilustram algumas das atividades realizadas em sala de aula, como o cantinho de leitura organizado por docente e alunos, a apresentação do roteiro no quadro pela professora, a realização da hora do conto e leitura livre, exibição de contação por meio do projetor e uma produção textual sobre um dos projetos desenvolvidos.

Fig. 01 - cantinho de leitura

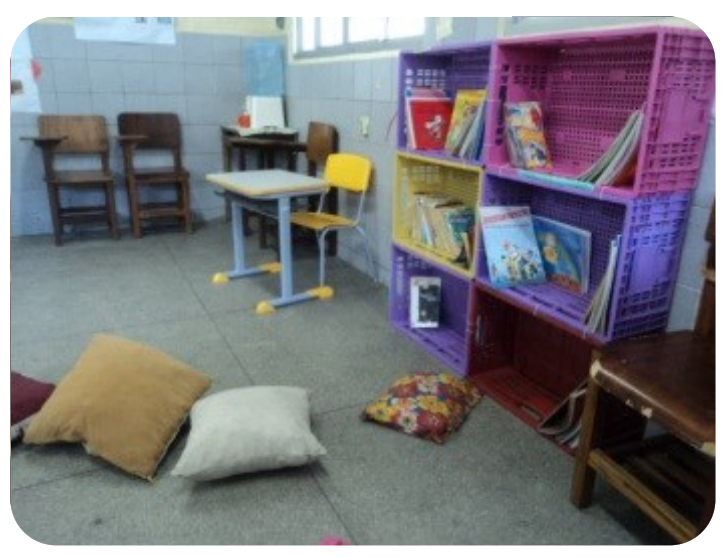

Fig. 03 - hora do Conto

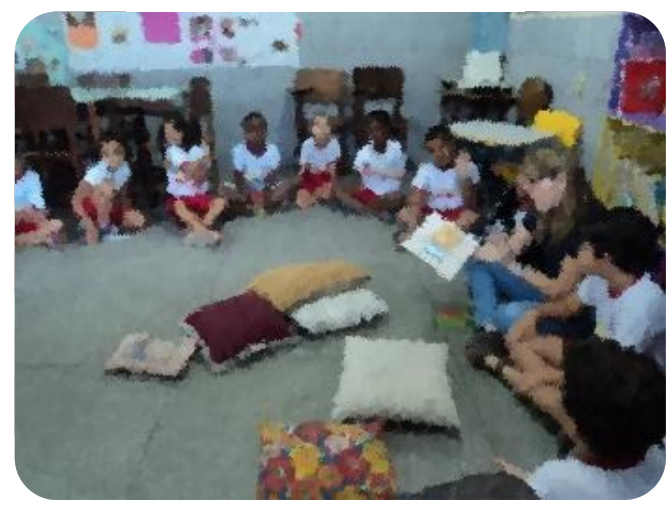

Fig. 02 - escrita do roteiro no quadro

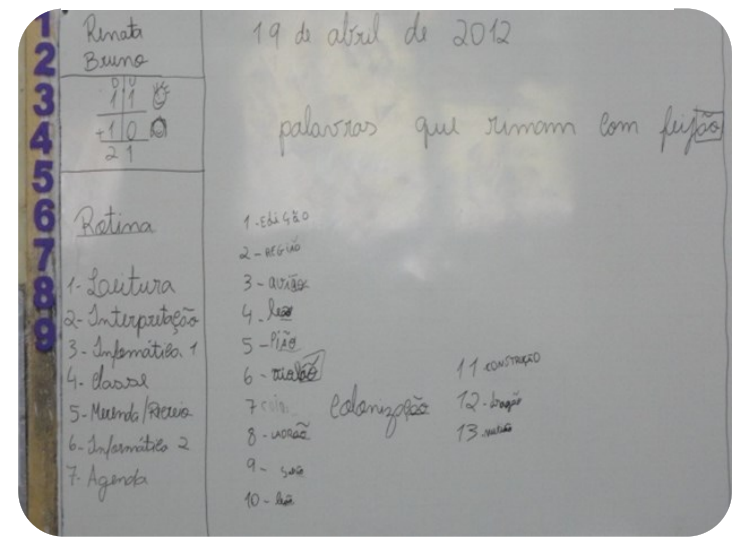

Fig. 04 - leitura livre

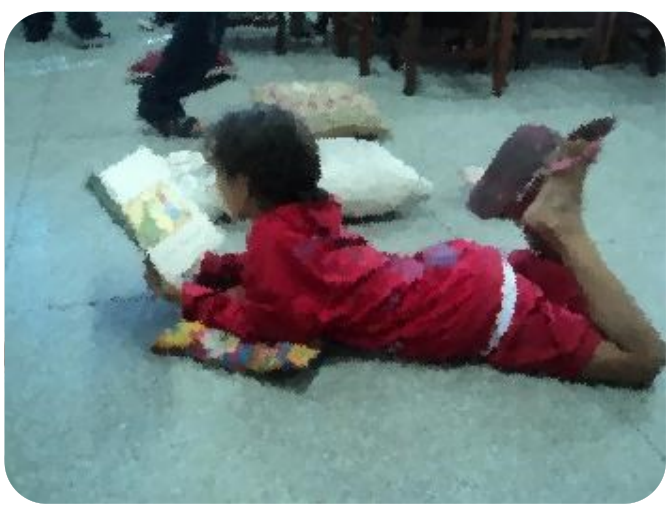


Fig. 05 - vídeo com contação de história

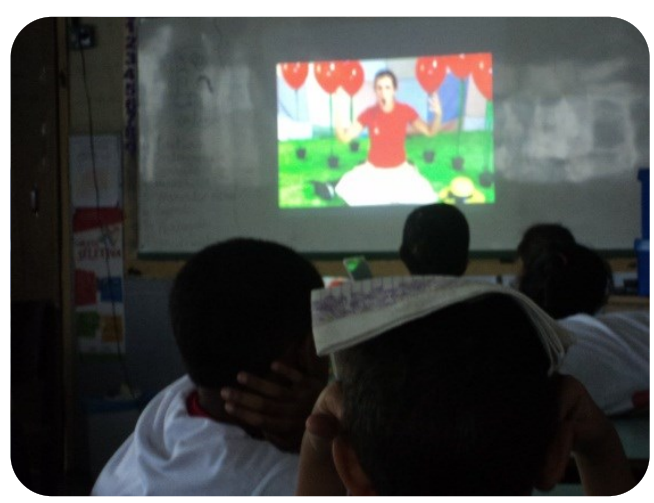

Fig. 06 - produção textual sobre preservação/ Projeto Reciclagem

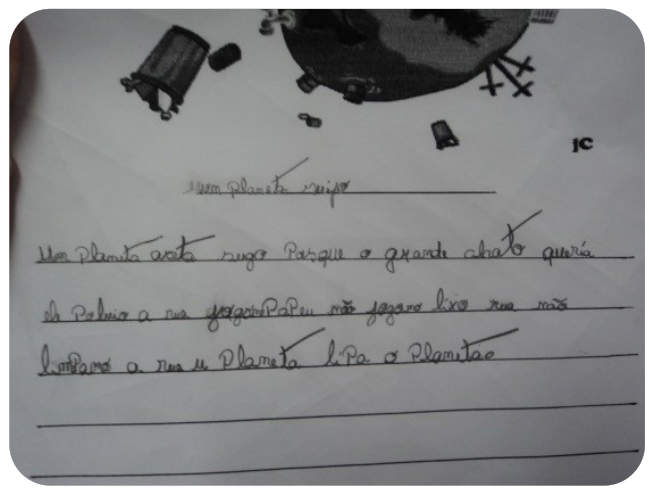

A turma observada contava com cerca de vinte e dois alunos frequentando as aulas. A docente havia realizado um diagnóstico com os alunos que apontava para a existência de crianças em diferentes hipóteses de escrita. Dessas crianças, poucas haviam atingido a compreensão da escrita alfabética. Sobre isso, a professora, em diversos momentos, introduzia a mesma atividade para a turma de forma adaptada aos conhecimentos apresentados pelos discentes. Um exemplo foi a situação de uma leitura passada para casa no final de semana, em que todos os alunos levaram uma leitura para "ensaiarem". Na segunda-feira, dia da observação, os alunos apresentaram sua leitura logo após a roda de conversa (registrada na figura 07 a seguir).

Fig. 07 - Crianças com ficha de leitura adaptada em mãos para apresentar na roda de conversa

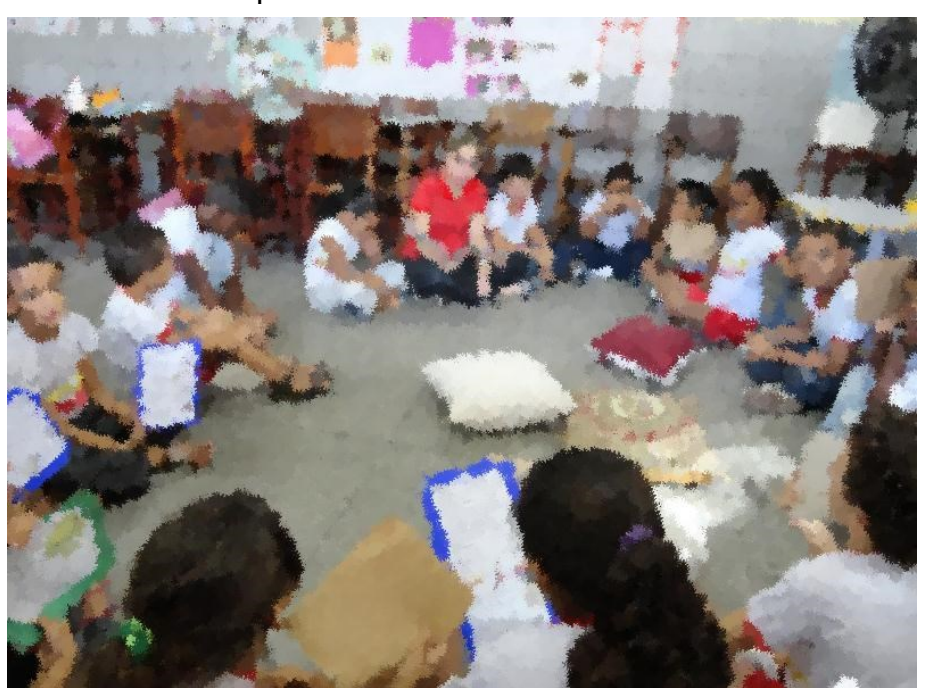


Cada texto apresentado fora selecionado pela docente de forma a adequar-se às hipóteses de leitura e escrita reveladas pelos alunos, ou seja, aos que se apresentavam muito no início do processo de alfabetização, ela destinou textos rimados e alguns que os discentes sabiam de cor; aos que já se apropriavam da leitura e da escrita com autonomia, ela entregou textos nos quais o esforço para a decodificação fosse o foco. Como é possível identificar nas figuras 8 e 9, houve a distribuição de materiais de leitura com extensões e dificuldades diferentes para atender aos níveis apresentados pelos alunos.

Figs. 08 e 09 - Fichas de leitura com os discentes. Observe-se que os textos possuem extensões e propostas diferentes.
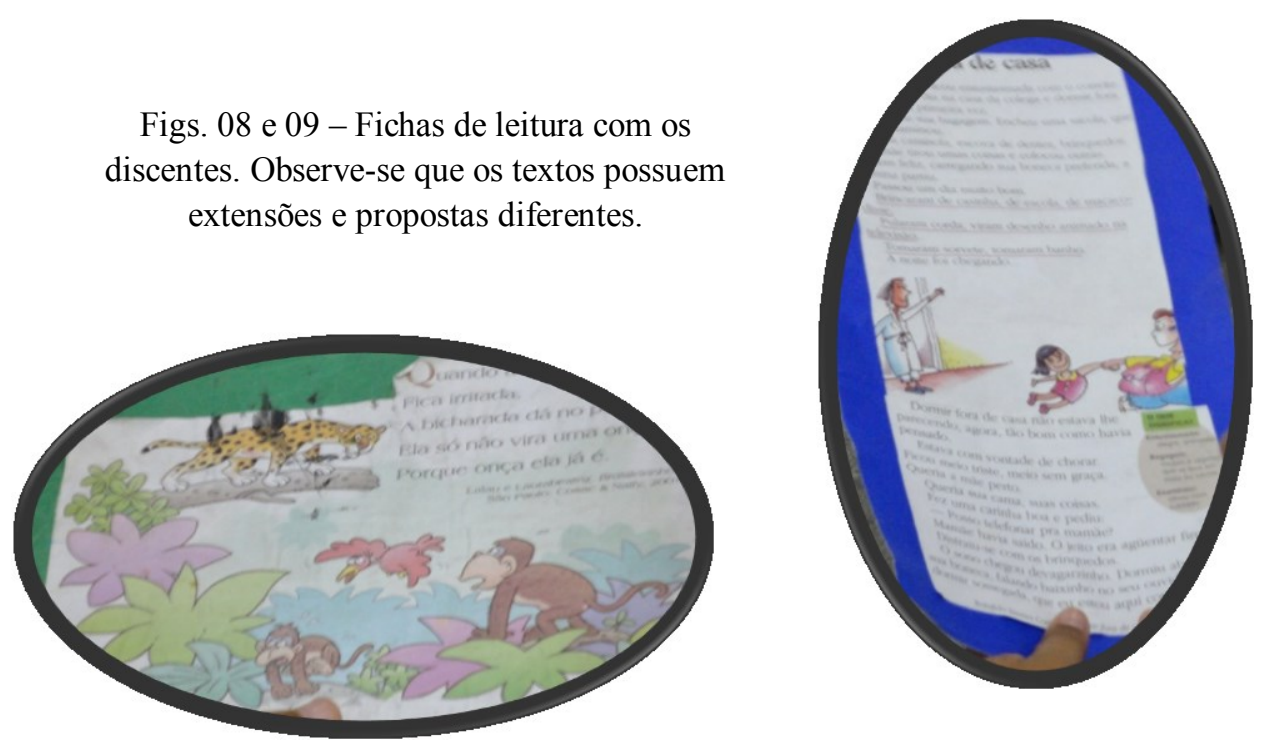

Em específico, uma variedade de ações didáticas em prol da aprendizagem da leitura pôde ser identificada nessas doze aulas observadas. É preciso salientar que sua prática revela uma preocupação em gerar demandas de situações de uso dos gêneros discursivos miméticas às situações reais de uso destes gêneros. Estas circunstâncias eram apresentadas aos discentes, que as recebiam com entusiasmo e se empenhavam em desenvolver as atividades orientadas pela docente. Dessa forma, se elencavam sequências de comandos de leitura, análise linguística e produções textuais (orais e escritas). Destaque-se, inclusive, que geralmente as produções textuais dos alunos estavam voltadas ao atendimento de uma situação com interlocutores reais e de interesse dos discentes, como por exemplo, numa das sequências de suas aulas, os discentes foram levados a ler diversos trava-línguas produzidos por Eva Furnari e, posteriormente, a docente solicitou destes a produção de trava-línguas que seriam enviados a esta autora. 
As ações voltadas para o ensino da leitura eram garantidas na organização diária do cantinho de leitura (manuseio das obras pelos alunos, leituras livres, posse temporária das obras, por exemplo), na hora do conto (professora todos os dias levava os alunos a sentarem-se no chão e realizavam a leitura de contos, poemas, dentre outros) e em outras atividades esporádicas, como na realização das fichas de atividades, no uso do livro didático, na escuta e leitura de músicas. A atividade de maior recorrência nas aulas observadas, a "hora do conto", merece, neste momento, um destaque. A docente produziu uma situação de leitura continuada para "A hora do Conto" no mês de outubro, ou seja, já nos meses de finalização das atividades letivas do ano. Inseriu uma obra mais extensa de forma a garantir o contato dos alunos com esse formato de texto e de modo a, mesmo antes de acessá-lo com autonomia, promover o interesse pela leitura, bem como a aprendizagem das estratégias de leitura. Vejamos um recorte de aula nos quadros abaixo:

Às $8 \mathrm{~h} 25 \mathrm{~min}$, organizaram a roda de leitura e a docente iniciou a leitura de mais um capítulo do livro "o menino que caiu no buraco".

P:----“A gente tá lendo qual historia?"

A:---"do menino que caiu no buraco"

P:----“e o que foi que aconteceu, nessa história?"

A:----"ele seguiu a borboleta azul"

P:----“ah, ele seguiu uma borboleta azul e foi parar aonde?"

A----"no buraco"

A2:----"dentro do buraco"

A3:---“"não, numa fabrica"

P:----"numa fábrica..."

A:----"velha"

P:----"numa fábrica velha... Tava aberta essa fábrica?"

T:----"não!!!"

P:----“a fábrica era de quê?"

A:----"de panela de barro"

P:----“uma fábrica de panela, de barro. E aí, ele seguiu a borboleta azul.... Ele achou a borboleta?" (...)

P:----“aí, a gente já leu quantos capítulos?”

A:----"três... Borboleta azul"

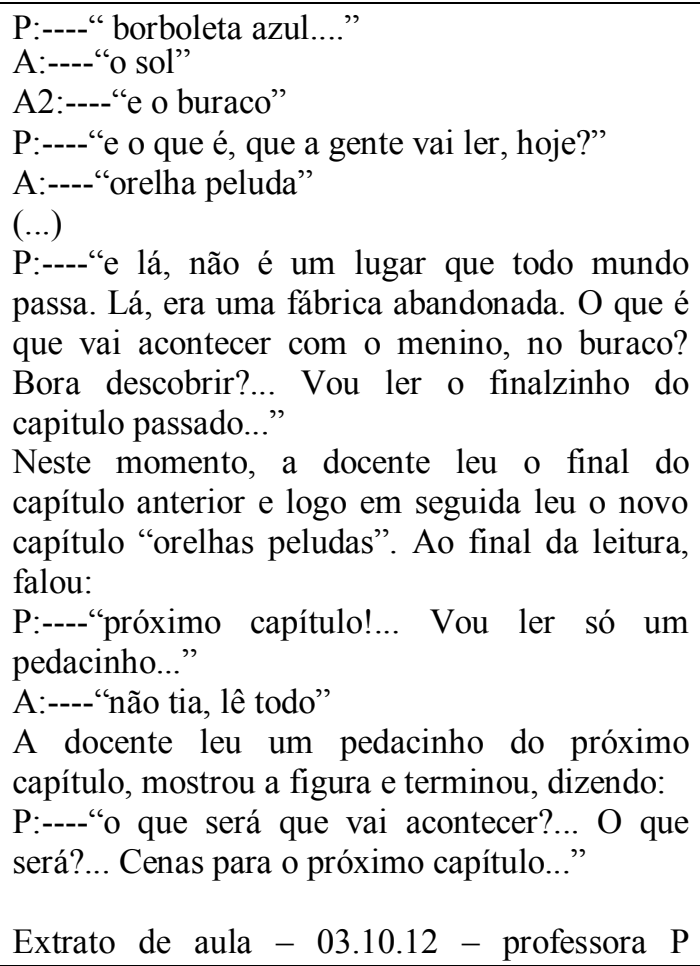

As ações da docente em estudo convergem com as abordagens presentes nos estudos de Chartier (2007) quando a autora salienta que para a instauração de práticas de leitura torna-se fundamental levar os alunos não só ao acesso, mas também ao reconhecimento dessas práticas no cotidiano da sociedade. Essa perspectiva se revela no uso diário da leitura e da escrita em sala de aula, com as escolhas por situações reais de 
interlocução para dar finalidade às situações mais "escolarizadas" de leitura e escrita propostas em sala de aula. É importante ressaltar a adesão dos alunos nas propostas da docente como um fator importante para possibilitar a aprendizagem dos conteúdos propostos.

\section{À GUISA DE CONCLUSÕES}

As escolhas e ações didáticas, no que concerne às práticas alfabetizadoras apresentadas aqui, remontam às perspectivas apontadas por Cruz (2008); Albuquerque, Morais e Ferreira (2008) acerca da necessidade de conjugação das propostas de leitura e produção de textos às ações de alfabetizar.

Em paralelo às atividades de análise linguística com objetivos voltados à alfabetização, a docente constituía uma prática contínua em sala de aula que promovia a construção de um leitor atento ao gerenciamento de sua compreensão acerca do texto lido e competente no uso das estratégias. Ao mesmo tempo se fazia presente, também articuladas às situações sociais de uso da escrita, as propostas voltadas ao ensino da escrita alfabética.

Dentro dos limites impostos pela própria aprendizagem da leitura e da escrita alfabética e diante do descortinar das ações e escolhas realizadas por essa docente comprometida com uma prática centrada no alfabetizar letrando, é possível compreender um movimento de reconfiguração do ensino da alfabetização.

\section{REFERÊNCIAS}

ALBUQUERQUE, E.B.C; MORAIS, A.G; FERREIRA, A.T.B. As práticas cotidianas de alfabetização: o que fazem as professoras?. Revista Brasileira de Educação, v. 13, N.38, p. 252-264, mai-ago 2008.

BARDIN, Laurence. Análise de Conteúdo. Lisboa: Edições 70, 1977.

BRASIL, Ministério da Educação. Pacto Nacional pela Alfabetização na Idade Certa. Brasília: MEC, 2012.

CHARTIER, Anne-Marie. Dos abecedários aos métodos de leitura: gênese do manual moderno antes das leis Ferry. In CHARTIER, Anne-Marie. Práticas de leitura e escrita: história e atualidade. BH: Ceale/Autêntica, 2007.

CRUZ, M. C. Alfabetizar letrando: alguns desafios do $1^{\circ}$ ciclo no ensino fundamental. Recife: EDUFPE, 2008. 
COLOMER, T.; CAMPS, A. Ensinar a ler, ensinar a compreender. Porto Alegre: Artmed, 2002.

FERREIRO, E. Reflexões sobre alfabetização. 24ª Edição. SP: Cortez, 2001.

LANKSHEAR, Colin \& KNOBEL, Michele. Pesquisa Pedagógica: do projeto à implementação; tradução: Magda França Lopes. POA: Artmed, 2008.

MORTATTI, M.R.L. Os sentidos da alfabetização (São Paulo: 1876-1994). SP: Ed. UNESP; CONPED, 2000.

SEAL, Ana Gabriela de Souza. Práticas de Leitura nos Anos 1 e 2 do Ensino Fundamental: ações docentes para alfabetizar letrando. Projeto de Pesquisa. UFERSA: Mossoró, 2012.

SOARES, M. Letramento: um tema em três gêneros. BH: Autêntica, 1998.

SOARES, M.. Letramento e alfabetização: as muitas facetas. In: $26^{\text {a }}$ Reunião Nacional da ANPEd, 2003, Caxambu. Anais da $28^{\mathrm{a}}$ Reunião Nacional da ANPEd, Caxambu: 2003a, p. $1-18$.

SOLÉ, Isabel. Estratégias de leitura. POA: Editora Artmed, 1998.

\section{A AUTORA}

Ana Gabriela de Souza Seal é Pedagoga e Mestre em Educação pela Universidade Federal de Pernambuco. Professora Adjunta do curso de Licenciatura em Educação do Campo da Universidade Federal Rural do Semi-Árido (LEDOC-UFERSA), no qual atua desde 2013. Produziu materiais didáticos de formação docente para o Programa Nacional de Alfabetização na Idade Certa. É vinculada ao Centro de Estudos em Educação e Linguagem (CEEL-UFPE) pelo qual participou da elaboração de projetos e materiais didáticos para as redes públicas municipais e estaduais, bem como ministrou cursos de formação sobre o ensino da linguagem na educação infantil e ensino fundamental.

E-mail: anagseal@ufersa.edu.br 